\title{
Elevated expression of LAG-3, but not PD-1, is associated with impaired iNKT cytokine production during chronic HIV-1 infection and treatment
}

\author{
Jennifer A Juno ${ }^{1}$, Andrew T Stalker ${ }^{1}$, Jillian LM Waruk ${ }^{2}$, Julius Oyugi ${ }^{1,3}$, Makobu Kimani ${ }^{1,3}$, Francis A Plummer ${ }^{1,4}$,
} Joshua Kimani ${ }^{1,3}$ and Keith R Fowke ${ }^{1,3,4^{*}}$

\begin{abstract}
Background: $L A G-3$ is a potent negative regulator of the immune response but its impact in HIV infection in poorly understood. Unlike exhaustion markers such as PD-1, Tim-3, 2B4 and CD160, LAG-3 is poorly expressed on bulk and antigen-specific T cells during chronic HIV infection and its expression on innate lymphocyte subsets is not well understood. The aim of this study was to assess LAG-3 expression and association with cellular dysfunction on T cells, NK cells and iNKT cells among a cohort of healthy and HIV-infected female sex workers in Nairobi, Kenya.

Results: Ex vivo LAG-3 expression was measured by multiparametric flow cytometry, and plasma cytokine/chemokine concentrations measured by bead array. Although LAG-3 expression on bulk T cells was significantly increased among HIV-infected women, the proportion of cells expressing the marker was extremely low. In contrast, LAG-3 was more highly expressed on NK and iNKT cells and was not reduced among women treated with ART. To assess the functional impact of LAG-3 on iNKT cells, iNKT cytokine production was measured in response to lipid (aGalCer) and PMA/lo stimulation by both flow cytometry and cytokine bead array. iNKT cytokine production is profoundly altered by both HIV infection and treatment, and LAG-3, but not PD-1, expression is associated with a reduction in iNKT IFNY production.

Conclusions: LAG-3 does not appear to mediate T cell exhaustion in this African population, but is instead expressed on innate lymphocyte subsets including iNKT cells. HIV infection alters iNKT cytokine production patterns and LAG-3 expression is uniquely associated with iNKT dysfunction. The continued expression of LAG-3 during treatment suggests it may contribute to the lack of innate immune reconstitution commonly observed during ART.
\end{abstract}

Keywords: Exhaustion, iNKT cells, LAG-3 protein human, HIV, CD223, Immune dysfunction

\section{Background}

During chronic HIV infection, persistent antigen exposure, microbial translocation and increasing immune activation lead to the phenomenon of immune exhaustion, where lymphocyte subsets (most commonly CD8+ T cells) exhibit a progressive loss of cytotoxicity, cytokine production and proliferation (reviewed in [1]). The phenotype of immune exhaustion is often mediated by the increased and simultaneous expression of inhibitory surface proteins such as PD-1, Tim-3, LAG-3, CD160

\footnotetext{
* Correspondence: keith.fowke@med.umanitoba.ca

'Department of Medical Microbiology, University of Manitoba, 539 - 745 Bannatyne Avenue, Winnipeg, Manitoba R3E 0 J9, Canada

${ }^{3}$ Department of Medical Microbiology, University of Nairobi, Nairobi, Kenya Full list of author information is available at the end of the article
}

and 2B4/CD244 on CD4+ and CD8+ T cells. Initiation of combination antiretroviral therapy (cART) often returns inhibitory receptor levels to baseline [2,3], and blockade of these pathways during infection is being considered as a component of viral eradication strategies [4].

In contrast to highly studied markers such as PD-1 and Tim-3, less is known about the expression and role of LAG-3 in immune exhaustion during chronic HIV infection. The LAG-3 protein bears structural similarities to $\mathrm{CD} 4$ and binds the same ligand, MHC class II, but with much greater affinity [5-7]. LAG-3 cross-linking inhibits $\mathrm{Ca}^{2+}$ fluxes, $\mathrm{T}$ cell proliferation and IFN $\gamma$, TNF $\alpha$ and IL-2 (but not Th2 cytokine) production following TCR re-stimulation $[8,9]$. In healthy individuals, its ex vivo 
expression is negligible, but it is known to be expressed on activated T and NK cells [5,10], Tregs [11,12], iNKT cells [13] and some pDC populations [14]. Microarray studies of gene expression during multiple stages of HIV/SIV infection indicate modulation of LAG-3 expression [15,16]; LAG-3 transcript levels positively correlate with viral load set point and are significantly higher among rapid progressors compared to viremic non-progressors [17]. In vitro, HIV-pulsed DCs can induce the expression of a number of exhaustion markers, including LAG-3, on T cells [18].

Despite these observations, evidence of LAG-3 involvement in lymphocyte dysfunction during chronic infection remains elusive. With the exception of one report [19], early studies suggested that LAG-3 is not upregulated on bulk $\mathrm{T}$ cells during HIV infection [20]. Recent characterization of HIV-specific $\mathrm{T}$ cells found that the major populations of exhausted HIV-specific CD8+ and CD4+ T cells lack LAG-3 expression [21,22]. Although a recent study reported on a population of LAG-3+ HIV-specific CD8+ T cells associated with low viral loads, the authors were unable to detect LAG-3 expression on $\mathrm{HIV}$-specific $\mathrm{T}$ cells prior to a 30 hour stimulation in vitro [23].

Importantly, LAG-3 expression on non-T lymphocyte subsets during chronic HIV infection has not been assessed. In HIV infection, NK cells exhibit multiple functional defects $[24,25]$ that persist during cART [26], as well as expansion of a dysfunctional $\mathrm{CD} 56^{-} \mathrm{CD} 16^{+}$ subset that expresses high levels of inhibitory receptors [27]. The invariant NKT (iNKT) population is also affected by HIV infection. iNKTs are innate lymphocytes and a small subset of CD1d-restricted CD3+ lymphocytes that respond to lipid antigen stimulation with robust cytokine production and proliferation, creating a potent link between the innate and adaptive arms of the immune system. CD4+ iNKTs are depleted during chronic HIV infection $[28,29]$ and exhibit variable reconstitution during ART [28,30,31]. The bulk iNKT population displays also defects in IFN $\gamma /$ TNF $\alpha$ secretion and proliferation [30,32-34]. The consequences of iNKT dysfunction or exhaustion during infection could be considerable due to the unique role of iNKT cells in linking, and directing, innate and adaptive immunity. A hallmark of iNKT activation is the rapid production of a vast array of cytokines and chemokines [35-37]. Other iNKT effector functions include perforin/granzyme release associated with NKG2D engagement [38-42], and Fas/FasL-mediated cytotoxicity $[36,39]$. In addition to direct cytolytic function and cytokine secretion, iNKTs play an important role in the activation and regulation of other immune cell subsets. iNKT activation reciprocally modulates DC function [43-45] and quickly leads to NK cell activation in an IFN $\gamma$-dependent manner, followed by T and B cell activation [46]. Stimulation of iNKT cells in conjunction with soluble $\mathrm{T}$ cell antigen enhances both CD4+ and CD8+ antigen-specific responses $[47,48]$.

Consequently, loss of iNKT function can lead to significant defects in adaptive immunity. Data from nonhuman primate studies suggests that pre-infection iNKT frequency correlates with retention of CD4 count following SIV challenge, and supernatant from iNKT cultures is sufficient to inhibit HIV replication in vitro. To date, the determinants of iNKT dysfunction during HIV infection are poorly understood. In one study, the exhaustion marker PD-1, which contributes to loss of $\mathrm{T}$ cell function in HIV infection, was unrelated to iNKT dysfunction [30], but the role of other inhibitory receptors such as LAG-3 has not been assessed.

In this context, several gaps in knowledge remain. Although T cell LAG-3 expression is generally low, no studies to date have included cohorts of African populations where $\mathrm{T}$ cell immune activation is significantly higher compared to Caucasians [49] and HIV clade A/ $\mathrm{D} / \mathrm{C}$ infections predominate. We also extended our studies of LAG-3 expression beyond CD4+ and CD8+ T cells, given reports of LAG-3 expression on activated NK and ex vivo iNKT cells and simultaneously assessed LAG-3 expression on T cell, NK and iNKT subsets among a population of healthy and HIV-infected Kenyan commercial sex workers. In a follow-up study, we determined the functional consequences of the association between LAG-3 expression and iNKT cytokine production in chronically infected and ART-treated individuals. This is the first study to functionally assess LAG-3 on multiple lymphocyte populations among an African cohort.

\section{Results}

\section{LAG-3 Expression screening study}

A total of $10 \mathrm{HIV}-, 40 \mathrm{HIV}+$ ART naïve and $40 \mathrm{HIV+}$ ART experienced women were recruited for the study (Table 1). The gating strategy for ex vivo samples is shown in an (Additional file 1). CD3+ and CD3- subsets were identified by histogram gating. iNKT cells were identified as $\mathrm{CD} 3+6 \mathrm{~B} 11+$, while conventional $\mathrm{T}$ cells were identified as $\mathrm{CD} 3+6 \mathrm{~B} 11$ - and further subgated based on CD4 and CD8 expression. NK cells were gated as CD56 ${ }^{\text {hi }}$ CD16-, CD56 ${ }^{\text {dim }}$ CD16+ or CD56-CD16+ within the CD3- population.

We first assessed LAG-3 expression on bulk CD4+ and CD8+ T cell subsets (Figure 1A). Consistent with reports in Caucasian populations [21], LAG-3 expression was negligible among healthy participants (median $0.14 \%$ CD4 + LAG-3+ and 0.165\% CD8 + LAG-3+) (Figure 1B). LAG-3 expression was significantly affected by HIV infection on both subsets ( $p=0.017$ for CD4+, 0.018 for CD8+), with significant post-test differences between the HIV-N and HIV+ ART groups ( $p<0.05$ for $\mathrm{CD} 4+$ and CD8+) (Figure 1B). Despite the significant differences, LAG-3 
Table 1 Characteristics of cohort subjects included in the screening study

\begin{tabular}{lllll}
\hline & HIV-N & HIV+ ART naïve & HIV+ ART experienced & p value $^{* *}$ \\
\hline Age, years $^{*}$ & $31.5(28.75,41)$ & $37(32.5,41)$ & $40(34,45.25)$ & 0.164 \\
Duration of sex work, years $^{*}$ & $9(5.25,13.5)$ & $7(5,14)$ & $11.5(5,19)$ & 0.552 \\
CD4 Count $^{*}$ & - & $428(369.3,632.3)$ & $354(245,481)$ & $\mathbf{0 . 0 1 1}$ \\
Duration of ART, years $^{*}$ & - & - & $2.14(1.16,3.64)$ & - \\
\hline
\end{tabular}

*Data are presented as median (IQR).

${ }^{* *}$ Groups were compared by Kruskal-Wallis test (age, duration of sex work) or Mann-Whitney test (CD4 count).

expression remained extremely low among all three participant groups ( $<2 \%$ of $\mathrm{CD} 4+$ or $\mathrm{CD} 8+$ population).

Exhaustion marker expression typically correlates with disease progression, whether measured by viral load, CD4 count or immune activation [50,51]. Because viral load determination is not performed as the standard of care in Kenya and was not available for these participants, CD4 count and CD8+ T cell activation (measured by HLA DR expression) were used as surrogates of disease progression. LAG-3 expression did not correlate with CD4 count on either CD4+ or CD8+ T cells among either group of HIV+ participants ( $p>0.1$ for all $\mathrm{HIV}+, \mathrm{HIV}+$ ART naïve and HIV+ ART experienced) (Figure 1C). Similarly, LAG-3 expression did not correlate with CD8+ HLA DR expression on any cell subset among any HIV+ groups (not shown). In addition to CD8+ T cell activation being an indicator of disease progression, LAG-3 is reported to be expressed primarily on activated $\mathrm{T}$ cells.

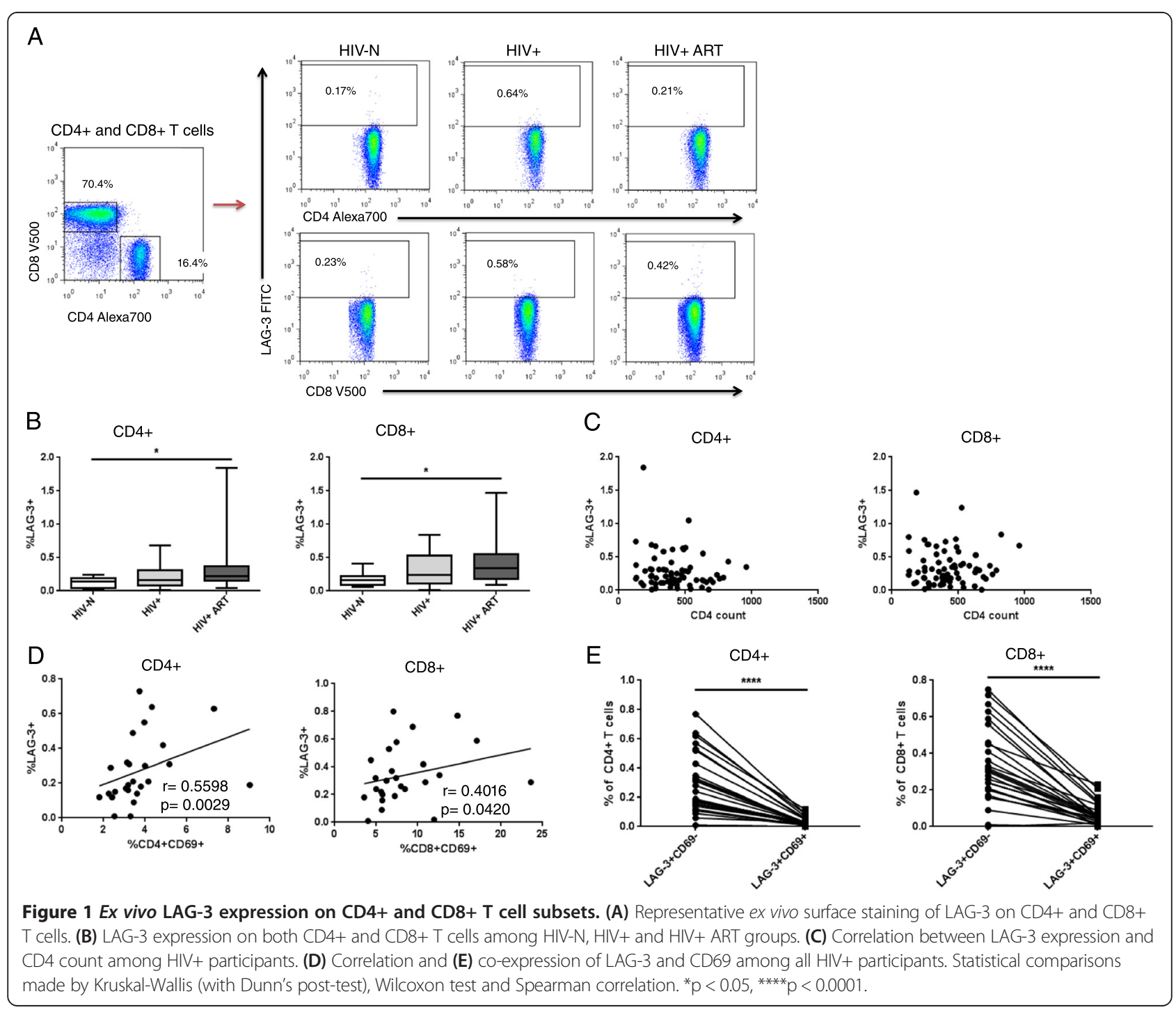


Therefore, we also assessed the correlation between LAG-3 expression and acute CD4+ and CD8+ $\mathrm{T}$ cell activation measured by CD69 expression. Notably, LAG-3 and CD69 expression significantly correlated on both $\mathrm{CD} 4+$ and CD8 $+\mathrm{T}$ cells $(\mathrm{r}=0.560, \mathrm{p}=0.003$ for $\mathrm{CD} 4+; \mathrm{r}=0.402$, $\mathrm{p}=0.042$ for $\mathrm{CD} 8+$ ) (Figure 1D).

To confirm that the negligible T cell LAG-3 expression in this cohort was specific to LAG-3 and not due to aberrant expression of all exhaustion markers, we jointly assessed LAG-3 and PD-1 expression in a small followup study of 15 HIV-N, 8 HIV+ and $17 \mathrm{HIV}+$ ART participants.

Consistent with all published literature [21], PD-1 expression was robust among all participants and was increased on CD8+ T cells among HIV-infected participants compared to healthy controls $(\mathrm{p}=0.0425)$ (Additional file 2A). LAG-3 expression did not correlate with PD-1 expression on CD8+ T cells (Additional file 2B). CD8 + LAG-3+ T cells, however, expressed significantly more PD-1 than the bulk CD8+ T cell population $(\mathrm{p}<0.0001)$ (Additional file 2C), indicating that LAG-3 tends to be co-expressed with PD-1 on CD8+ T cells during HIV infection.

We next quantified LAG-3 expression on multiple NK cell subsets based on CD56 and CD16 expression. As shown in Figure 2A, NKs were defined as CD $56{ }^{\text {hi }} \mathrm{CD} 16^{-}$ (immunoregulatory), $\mathrm{CD} 56^{\mathrm{dim}} \mathrm{CD} 16^{+}$(cytotoxic) and $\mathrm{CD} 56^{-}$ $\mathrm{CD} 6^{+}$(dysfunctional/anergic) (based on [27,52]). While Tim-3 is reportedly expressed at high levels, particularly on CD56 ${ }^{\mathrm{dim}}$ NKs [53], LAG-3 expression should typically be restricted to activated NK cells. LAG-3 expression was detected at low levels on all NK subsets among healthy individuals (Figure 2A, B). HIV infection altered LAG-3 expression on both the $\mathrm{CD} 56^{\mathrm{dim}} \mathrm{CD} 16^{+}$and $\mathrm{CD} 56{ }^{\mathrm{hi}} \mathrm{CD} 16^{-}$ NK subsets, but not $\mathrm{CD} 56^{-} \mathrm{CD} 16^{+} \mathrm{NKs}\left(\mathrm{CD} 56^{\mathrm{dim}} \mathrm{CD} 16^{+}\right.$ $\mathrm{p}=0.0368, \mathrm{CD}_{5} 6^{\mathrm{hi}} \mathrm{CD} 16^{-} \mathrm{p}=0.0134, \mathrm{CD}^{-} 6^{-} \mathrm{CD} 16^{+} \mathrm{p}=$ 0.1474) (Figure 2C). As observed with $\mathrm{T}$ cell LAG-3 expression, the significant differences were between the HIV+ ART experienced women compared to healthy controls $\left(\mathrm{CD} 56^{\mathrm{dim}} \mathrm{CD} 16^{+} \mathrm{p}=0.0151, \mathrm{CD} 56{ }^{\mathrm{hi}} \mathrm{CD} 16^{-} \mathrm{p}<0.05\right)$.

The relationship between NK LAG-3 expression and CD4 count, ART duration and CD4 recovery was virtually identical to that described for $\mathrm{T}$ cell subsets, and exhibited no significant associations. Intra-participant comparison of LAG-3 expression across NK subsets revealed significantly higher LAG-3 expression on the $\mathrm{CD} 56^{-} \mathrm{CD} 16^{+} \mathrm{NK}$ subset compared to either the CD56 ${ }^{\mathrm{dim}}$ or CD56 ${ }^{\mathrm{hi}}$ populations. The differences remained significant when analysis was restricted to only HIV- individuals $(\mathrm{p}=0.0004$, posttest $\mathrm{p}<0.05$ for CD56- versus CD56dim, $\mathrm{p}<0.01$ for CD56- versus CD56hi) (Figure 2D) or when restricted to all HIV+ and HIV+ ART participants $(\mathrm{p}<0.0001$, not shown). A parametric ANOVA test for linear trend demonstrated a significant decline in LAG-3 expression across NK cell subsets with increasing CD56 expression (CD56- > CD56dim > CD56hi) $(\mathrm{p}<0.0001$, ANOVA test for linear trend).

Human iNKT population frequencies are highly variable, ranging from $<0.01 \%$ of $\mathrm{CD} 3+\mathrm{T}$ cells to $>1 \%$ in published reports $[13,54]$. We used an antibody specific to the iNKT TCR (6B11) that is routinely used for iNKT identification [55-62] and that provides results comparable to those obtained using CD1d tetramers [63] (Figure 3A). Unlike murine iNKTs, human iNKT cells can be subgrouped as $\mathrm{CD} 4+, \mathrm{CD} 8 \alpha+$ or double negative (DN) [13]. Some samples contained too few iNKT events for further analysis, thereby reducing sample sizes for this analysis to 8 HIV-N, $34 \mathrm{HV}+$, and 34 HIV+ ART participants. Similar to the depletion of conventional $\mathrm{CD} 4+\mathrm{T}$ cells during chronic HIV infection, CD4+ iNKTs are easily infected and depleted [28]. Consistent with previous reports, the proportion of CD4+ iNKT cells in this cohort was reduced in the HIV+ ART naïve group ( $p=0.0012$, posttest $\mathrm{p}<0.01$ for healthy vs. HIV+). Interestingly, CD4+ iNKT proportion remained low among HIV+ ART experienced participants $(\mathrm{p}<0.001$ for healthy vs. HIV+ ART experienced) (Figure $3 \mathrm{~B}$ ), suggesting no reconstitution of the CD4+ iNKT compartment in this population during ART. The proportionate decrease in CD4+ iNKT cells was associated with an inflated proportion of CD8+ iNKT cells $(\mathrm{p}=0.0005$, post-test $\mathrm{p}<0.01$ for healthy vs. HIV+, $\mathrm{p}<0.001$ for healthy vs. HIV+ ART experienced), while the frequency of DN iNKTs remained similar across groups (Figure 3B).

LAG-3 expression was detected at low levels on iNKTs among healthy women, and was significantly elevated during chronic HIV infection among ART experienced participants (Figure $3 \mathrm{C}, \mathrm{D})(\mathrm{p}=0.0274$, post-test $\mathrm{p}<0.05$ for HIV- versus HIV+ ART). LAG-3 expression on the bulk iNKT subset did not correlate with CD4 count among HIV+ participants, whether grouped together or stratified by ART use (Figure 3F) ( $>0.1$ for all). iNKT $\mathrm{CD} 4+/ \mathrm{CD} 8+/$ double negative subset analysis of participants with sufficient events in each gate demonstrated that LAG-3 expression was significantly increased only on the CD4+ iNKT subset among HIV+ ART experienced individuals $(\mathrm{p}=0.029$, post-test $\mathrm{p}<0.05 \mathrm{HIV}$ - versus HIV+ ART) (Figure 3E). Among all HIV+ participants, iNKT LAG-3 expression did significantly correlate with iNKT activation as measured by CD69 expression (Figure 3G) $(\mathrm{r}=0.4507, \mathrm{p}=0.0353)$.

Given that LAG-3 expression was largely unrelated to HIV disease progression, we assessed whether LAG-3 expression on any lymphocyte subset was related to plasma concentrations of IFN $\alpha 2$, IFN $\gamma$, IL-4, IL-6, IL-10, MIP-1 $\beta$, sCD40L and TNF $\alpha$ quantified by cytokine bead array. Among participants with detectible analyte levels, iNKT LAG-3 expression exhibited a weak negative 


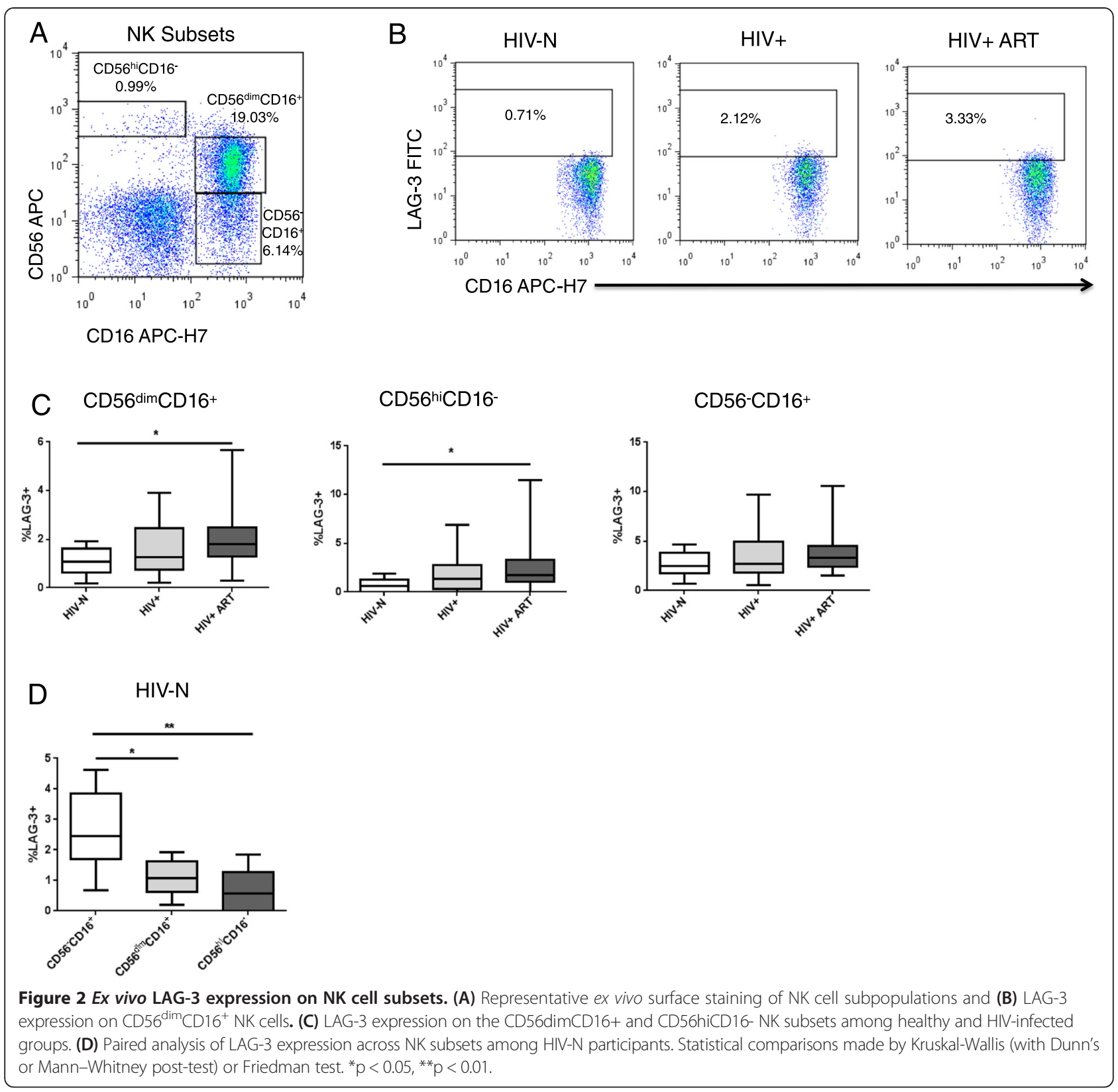

correlation with plasma IL-10 concentrations among HIVinfected participants as well as only ART experienced participants $(\mathrm{r}=-0.4291, \mathrm{p}=0.0463$ for $\mathrm{HIV}+\mathrm{HIV}+\mathrm{ART}$; $r=-0.6210, p=0.0438$ for HIV+ ART) (Figure $3 \mathrm{H}$ ).

\section{Assessment of iNKT function}

Because LAG-3 was expressed at higher levels on iNKT cells than T cells or NK cells during HIV infection, we further explored the relationship between LAG-3 expression and iNKT cell function in HIV+ participants. A total of 16 HIV-uninfected, 9 HIV+ ART naïve, and 17 HIV+ ART experienced women were recruited for this follow-up study. The characteristics of these groups, including age, duration of sex work, CD4 count and duration of ART are described in Table 2.

Consistent with the screening study, LAG-3 expression was elevated on iNKT cells during HIV infection ( $\mathrm{p}=$ 0.004), and was not restored to baseline by ART, as posttests revealed significant differences between the HIV-N and HIV+ ART experienced groups $(\mathrm{p}<0.01)$ (Figure 4A). In contrast to LAG-3, iNKT PD-1 expression was similar across groups (Figure 4B). Among all participants, iNKT LAG-3 expression weakly but inversely correlated with PD-1 expression ( $p=0.023, r=-0.367)$, a relationship that persisted as a trend among HIV-infected (HIV+ and HIV+ ART) women $(\mathrm{p}=0.098)$ (Figure $4 \mathrm{C})$. Interestingly, the 


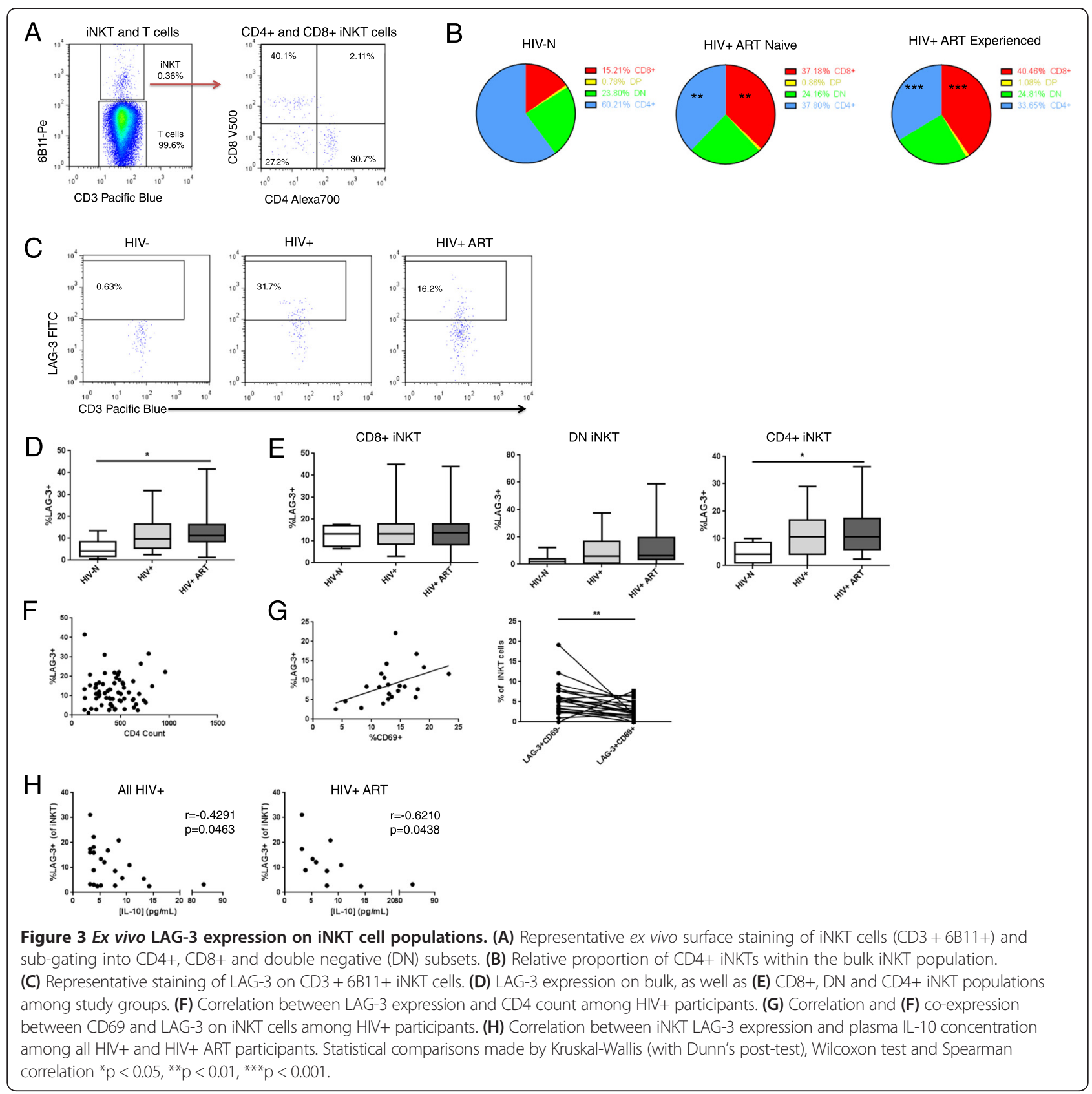

relationship between PD-1 and LAG-3 expression, and even PD-1 expression itself, on iNKT cells was distinct from the conventional CD8+ T cell subset. PD-1 expression on the iNKT subset was significantly higher than on CD8+ T cells among all participants $(\mathrm{p}<0.0001)$ or when stratified by HIV status ( $\mathrm{p}<0.0001$ for both HIV-N and combined HIV+ and HIV+ ART) (Figure 4D). Unlike the iNKT subset, PD-1 expression was significantly elevated on CD8+ T cells among HIV+ ART naive participants compared to healthy controls $(\mathrm{p}=0.010)$ (Figure $4 \mathrm{E})$ and no correlation between CD8+ T cell LAG-3 and PD-1 expression was observed among HIV+ participants $(\mathrm{p}=0.897)$ (Figure 4F).

\section{Assessment of iNKT cytokine production}

To assess iNKT cytokine production in the Majengo cohort, PBMC from HIV-, HIV+ and HIV+ ART experienced participants were stimulated with either the iNKT lipid antigen $\alpha$ GalCer or the mitogen PMA/Io. IFN $\gamma$ and TNF $\alpha$ were measured by intracellular flow cytometry (Additional file 3). Following stimulation with $\alpha \mathrm{GalCer}$, HIV status significantly affected IFN $\gamma$ production by 
Table 2 Characteristics of follow-up study participants

\begin{tabular}{lllll}
\hline Variable $^{*}$ & HIV-negative & HIV+ ART naïve & HIV+ ART experienced & p value $^{* *}$ \\
\hline Age, years & $40(34,44.5)$ & $35(29,41)$ & $40(34.5,44)$ & 0.522 \\
Duration of sex work & $10(6.5,12)$ & $9(5,14)$ & $11(8,20)$ & 0.324 \\
CD4 Count & - & $475.5(321,618)$ & $526.5(407,698)$ & 0.297 \\
Duration of ART & - & - & $3(3,5.5)$ & - \\
\hline
\end{tabular}

"Data are presented as median (IQR).

${ }^{* *}$ Groups were compared by Kruskal-Wallis test (age, duration of sex work) or Mann-Whitney test (CD4 count).

iNKT cells $(\mathrm{p}=0.019)$ (Figure 5A), with HIV+ ART naïve participants producing significantly less IFNy compared to healthy controls (post-test $\mathrm{p}<0.05$ ). IFNY production was only partially restored among the HIV+ ART group, as the median $\% \mathrm{IFN} \gamma+$ cells remained lower than that of healthy controls $(2.43 \%$ for HIV+ ART compared to $6.89 \%$ for HIV-N and $2.06 \%$ for HIV+). TNF $\alpha$ production was more similar across subject groups, with only a trend toward differences in cytokine production based on HIV status ( $\mathrm{p}=0.058)$ (Figure $5 \mathrm{~B})$. Similar to the results observed for IFN $\gamma$, the HIV+ ART naïve group exhibited the lowest median cytokine production $(1.29 \%$ TNF $\alpha$ + for HIV+ ART naïve compared to $4.74 \%$ for HIV-N and $5.62 \%$ for HIV+ ART). When analysing mono- versus dual-functional iNKT cells, HIV+ ART naive participants responded to stimulation with significantly fewer double positive TNF $\alpha+I F N \gamma+$ cells than healthy controls $(\mathrm{p}=0.030$, post-test $\mathrm{p}<0.05)$ (Figure $5 \mathrm{C}$ ), while the HIV+ ART group exhibited significantly fewer TNF $\alpha-I F N \gamma+$ cells in response to lipid stimulation compared to uninfected women $(\mathrm{p}=0.017$, post-test $\mathrm{p}<0.05)$ (Figure 5C).

Both bulk IFN $\gamma$ production and single-positive TNF $\alpha$ IFN $\gamma+$ cell frequencies inversely correlated with iNKT LAG-3 expression among HIV+ and HIV+ ART women $(\mathrm{p}=0.026, \mathrm{r}=-0.522$, and $\mathrm{p}=0.003, \mathrm{r}=-0.662$, respectively) (Figure 5D). In contrast, LAG-3 expression did not correlate with bulk TNF $\alpha$ (Figure 5E), TNF $\alpha+$ IFN $\gamma$ or TNF $\alpha+\mathrm{IFN} \gamma+$ responses (not shown). Ex vivo PD-1 expression did not significantly correlate with either bulk IFN $\gamma$ or TNF $\alpha$ cytokine production following stimulation (not shown).

When comparing cytokine expression between CD4+ and CD4- iNKT subsets, HIV-N individuals exhibited significantly higher IFNY production by $\mathrm{CD} 4+\mathrm{iNKTs}$ $(\mathrm{p}=0.006$, Figure $5 \mathrm{~F})$, a difference which was lost among HIV+ and HIV+ ART participants (Figure 5F). In contrast, TNF $\alpha$ production was equivalent between iNKT subsets in both the HIV-N and HIV+/HIV+ ART groups (Figure 5F). Despite subset-specific differences in IFN $\gamma$ production, ex vivo subset-specific LAG-3 expression inversely correlated with IFNY production for both the CD4+ $(\mathrm{p}=0.011, \mathrm{r}=-0.519)$ and CD4- $(\mathrm{p}=0.005, \mathrm{r}=-0.568)$ subsets (Figure $5 \mathrm{G}$ ). The correlation remained significant even after restricting analysis to $\mathrm{HIV}+$ and $\mathrm{HIV}+\mathrm{ART}$ participants only $(\mathrm{p}=0.040, \mathrm{r}=-0.663$ for $\mathrm{CD} 4+$ and $\mathrm{p}=$ 0.012, $r=-0.735$ for CD4-, not shown).

PMA/Io stimulation induced stronger cytokine responses compared to $\alpha \mathrm{GalCer}$ among all participant groups. Interestingly, IFN $\gamma$ secretion in response to PMA/Io stimulation varied significantly among groups $(\mathrm{p}=0.034)$ (Figure 6A). Although no significant intragroup differences were detected by Dunn's post-test, Mann Whitney comparison of each group demonstrated significantly lower IFN $\gamma$ production among both the HIV+ ART naïve and HIV+ ART groups compared to healthy controls $(\mathrm{p}=0.019$ and 0.041 , respectively). In contrast, PMA/Io-induced TNF $\alpha$ secretion was similar among all groups $(\mathrm{p}=0.334)$ (Figure $6 \mathrm{~B})$. The high levels of cytokine and LAG-3 expression induced by PMA/Io stimulation allows for a comparison of IFN $\gamma$ secretion by LAG-3+ and LAG-3- iNKT cells. Among all participants with sufficient iNKT cells for sub-gating, LAG-3+ iNKTs were significantly less likely to be IFNY + than LAG-3- iNKTs $(p=0.0005$, Figure $6 C)$, confirming an inhibitory activity of LAG-3 on IFN $\gamma$ production by iNKT cells.

5 day aGalCer-stimulated cytokine and SLAG-3 production To investigate the downstream consequences of iNKT dysfunction during HIV infection of PBMC cytokine/ chemokine production, we collected cell culture supernatants from 5 day iNKT $\alpha$ GalCer stimulations and quantified the expression of IFN $\gamma$, IL-4, IL-10, IL-13, IL-17, IP-10, MIP-1 $\alpha$, MIP-1 $\beta$, and TNF $\alpha$. IL-17 was detected above background by $<50 \%$ of participants in each group, and was therefore excluded from further analysis.

The proportion of individuals in each group demonstrating above-background expression of each analyte and the background subtracted concentration of each analyte are reported in Table 3 . Significant differences in analyte concentrations across groups were detected for IFN $\gamma$, IL-13 and IP-10 ( $\mathrm{p}=0.003,0.014$ and 0.001 , respectively, Figure 7A), and there was a trend toward a reduction in IL-4 concentration $(p=0.095)$. Post-tests revealed that inter-group differences were primarily significant for the HIV-N versus HIV+ ART experienced 

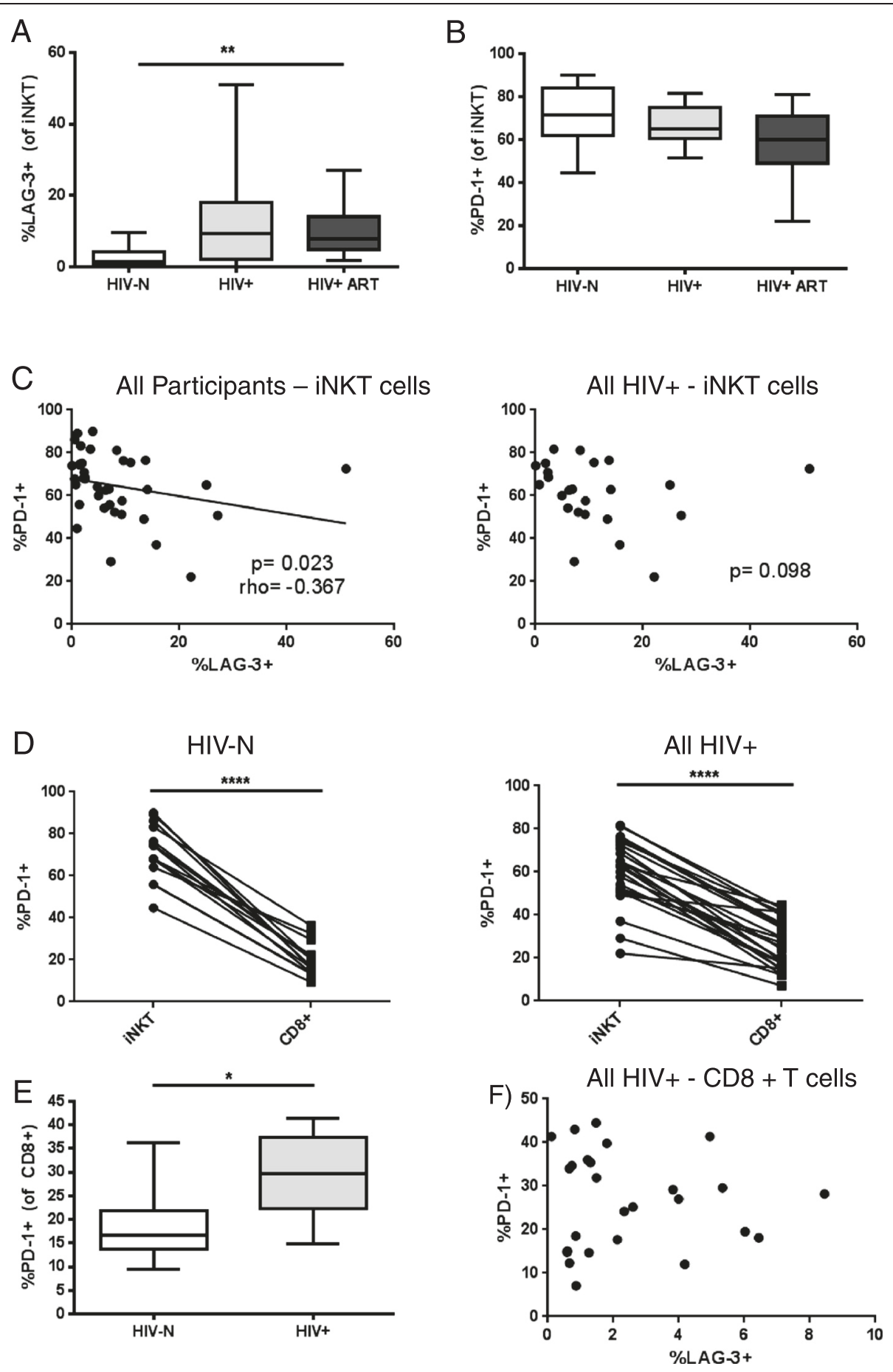

Figure 4 Baseline iNKT LAG-3 and PD-1 expression among healthy HIV-N $(n=14)$, HIV+ $(n=9)$ and HIV+ ART $(n=15)$ women. Comparison of (A) iNKT LAG-3 expression and (B) iNKT PD-1 expression among HIV-N, HIV+ and HIV+ ART groups in a follow-up study. (C) Correlation between LAG-3 and PD-1 expression all participants and HIV+/HIV+ ART women. (D) Comparison of PD-1 expression on iNKTs compared to conventional CD8+ T cells among both healthy and HIV-infected women. (E) PD-1 expression on CD8+ T cells among HIV+ ART naïve women $(n=9)$ compared to healthy controls $(n=16)$. (F) Correlation between LAG-3 and PD-1 on CD8+ T cells. Statistical comparisons made by Kruskal-Wallis (with Dunn's post-test), Wilcoxon test, Mann-Whitney and Spearman correlation ${ }^{*} p<0.05,{ }^{* *} p<0.01,{ }^{* * *} p<0.0001$. 


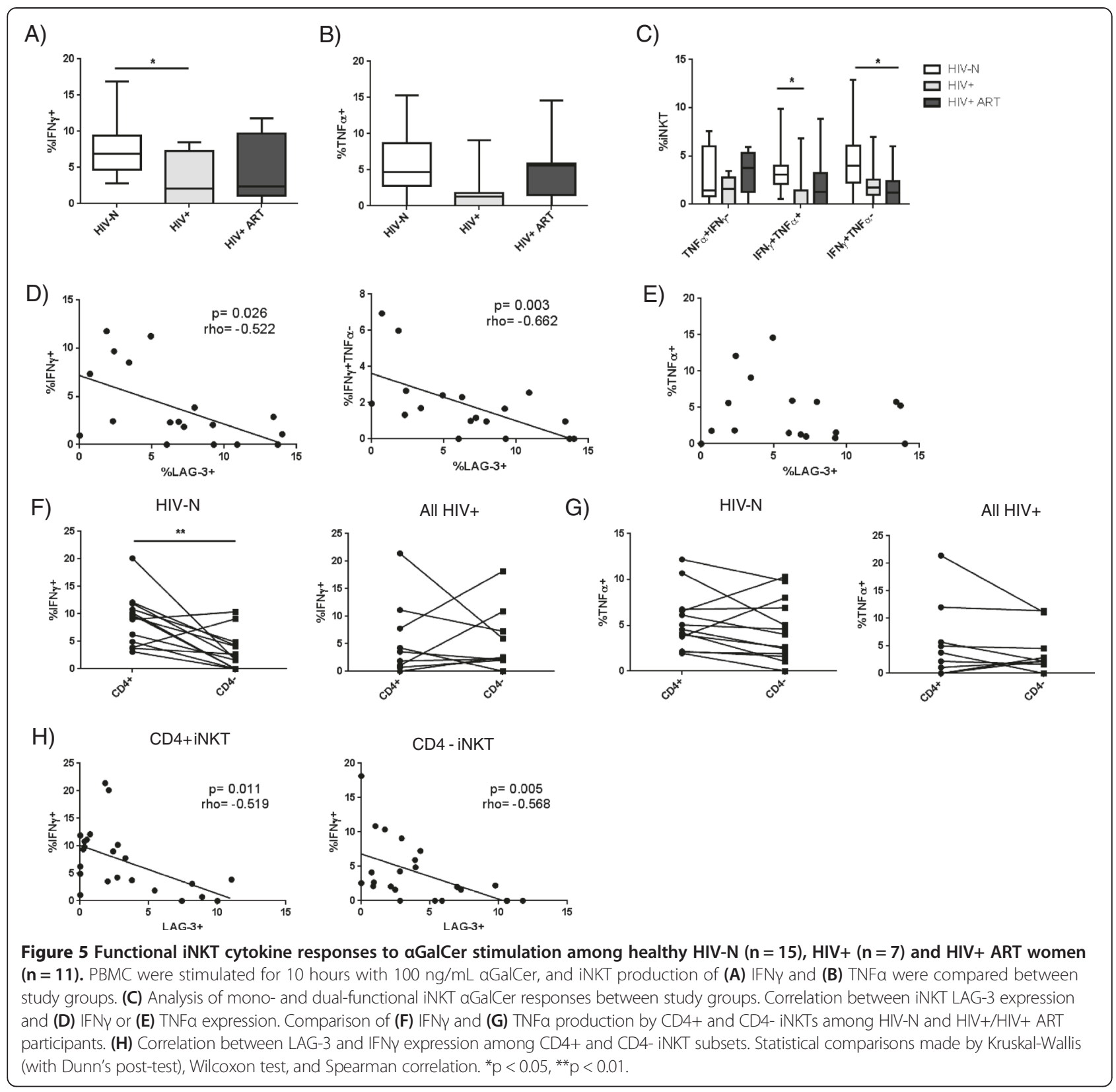

group comparisons ( $\mathrm{p}<0.01,<0.05,<0.001$, respectively). Given that iNKT activation contributes to NK, B and T cell activation, these cell types most likely contributed to the cytokine/chemokine milieu by 5 days post-stimulation. Ex vivo iNKT frequency significantly correlated with background-subtracted expression of all analytes except IL-10 (not shown), suggesting, that cytokine production was indeed iNKT-driven. Following adjustment for baseline iNKT frequency, significant differences between groups in IFN $\gamma(\mathrm{p}=0.009)$ and IP-10 ( $\mathrm{p}=0.006)$ expression remained, as well as a trend toward differences in IL-13 ( $\mathrm{p}=0.055)$ expression (not shown).
In addition to differences in absolute levels of cytokine production, some studies have described cytokine production patterns by expressing the contribution of each analyte as a proportion of the total cytokine production by a group [64]. In this analysis, the concentration of each analyte was summed across all members of a group, and expressed as a percent of the total cytokines produced by that group (Figure 7B). In the HIV-N group, the $\alpha \mathrm{GalCer}$-induced cytokine response is dominated by IP-10, IFN $\gamma$ and IL-13 expression. In contrast, the $\mathrm{HIV}+\mathrm{ART}$ naïve group demonstrated a relative expansion in the contribution of IP-10, MIP-1 $\alpha$ and 
A

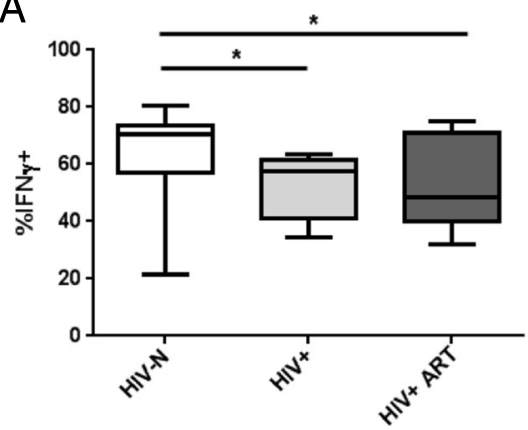

C

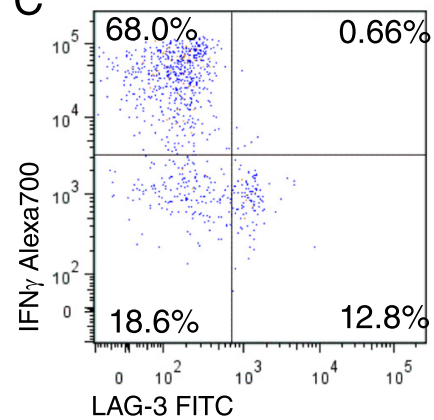

B
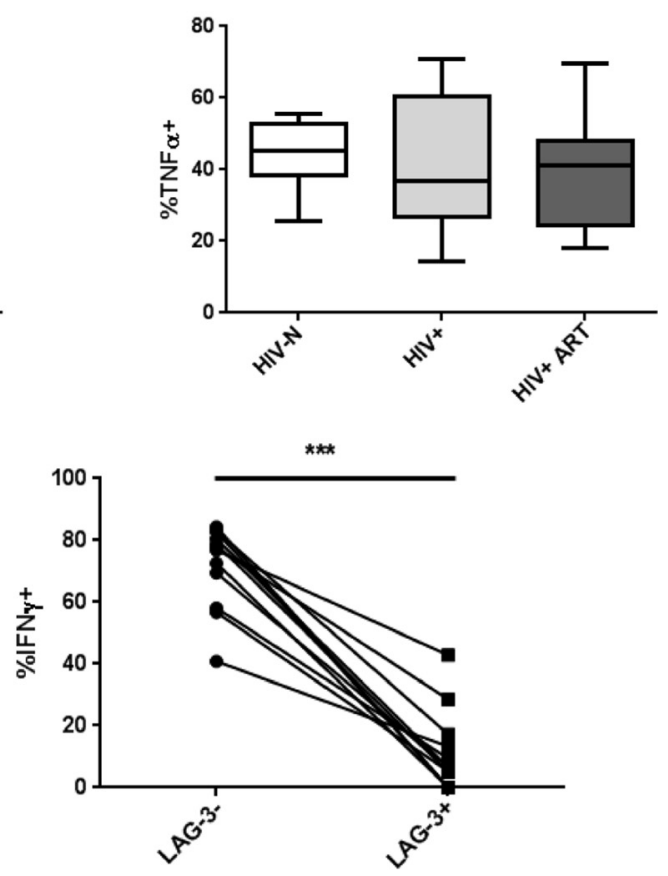

Figure 6 PMA/lo-induced iNKT functional responses. PBMC were stimulated for 6 hours with $25 \mathrm{ng} / \mathrm{mL}$ PMA and $500 \mathrm{ng} / \mathrm{mL} 10$, and iNKT (A) IFNy production and (B) TNFa production were compared among study groups. (C) Comparison of IFNy production by LAG-3+ and LAG-3- iNKTs among all participants. Statistical comparisons made by Kruskal-Wallis (with Mann-Whitney post-test), Wilcoxon test and Spearman correlation. ${ }^{*} p<0.05,{ }^{* * *} p<0.001$.

Table 3 Above-background cytokine responses to aGalCer at 5 days post-stimulation

\begin{tabular}{|c|c|c|c|c|c|c|}
\hline \multicolumn{2}{|l|}{ Analyte } & \multirow{2}{*}{$\begin{array}{l}\text { HIV-negative }(\mathbf{n}=\mathbf{1 4}) \\
13\end{array}$} & \multirow{2}{*}{$\frac{\text { HIV+ ART naïve }(n=8)}{7}$} & \multirow{2}{*}{$\begin{array}{l}\text { HIV+ ART experienced }(n=14) \\
8\end{array}$} & \multirow{2}{*}{$\begin{array}{l}\text { p value } \\
0.057\end{array}$} & \multirow[t]{2}{*}{ Post-test differences ${ }^{* * *}$} \\
\hline$\overline{I F N Y}$ & N Detectible & & & & & \\
\hline & Concentration $^{*}$ & $345.9(76.74,2115)$ & $34.97(4.83,142.7)$ & $2.275,(0.0,124.8)$ & 0.003 & HIV-N vs HIV+ ART \\
\hline \multirow[t]{2}{*}{$\mid \mathrm{L}-4$} & N Detectible & 7 & 3 & 2 & 0.129 & \\
\hline & Concentration $^{*}$ & $3.06(0.0,22.02)$ & $0.0(0.0,6.69)$ & $0.0(0.0,0.18)$ & 0.095 & \\
\hline \multirow[t]{2}{*}{ IL-10 } & N Detectible & 4 & 2 & 6 & 0.618 & \\
\hline & Concentration $^{*}$ & $0.0(0.0,5.82)$ & $0.0(0.0,4.25)$ & $0.0(0.0,13.8)$ & 0.683 & \\
\hline \multirow[t]{2}{*}{$\| \mathrm{L}-13$} & N Detectible & 11 & 5 & 6 & 0.152 & \\
\hline & Concentration $^{*}$ & $199.1(19.23,477.0)$ & $8.26(0.11,77.2)$ & $0.0(0.0,25.45)$ & 0.014 & HIV-N vs HIV+ ART \\
\hline \multirow[t]{2}{*}{$\mid \mathrm{P}-10$} & N Detectible & 11 & 6 & 5 & 0.005 & \\
\hline & Concentration $^{*}$ & $1586(836.8,6168)$ & $329.3(24.5,5351)$ & $0.0(0.0,409.6)$ & 0.001 & HIV-N vs HIV+ ART \\
\hline \multirow[t]{2}{*}{ MIP-1a } & N Detectible & 6 & 4 & 4 & 0.409 & \\
\hline & Concentration $^{*}$ & $0.0(0.0,198.4)$ & $37.2(0.0,158.5)$ & $0.0(0.0,75.6)$ & 0.453 & \\
\hline \multirow[t]{2}{*}{ MIP-1 $\beta$} & N Detectible & 8 & 4 & 4 & 0.368 & \\
\hline & Concentration $^{*}$ & $78.16(0.0,370.2)$ & $35.06(0.0,165.1)$ & $0.0(0.0,104.6)$ & 0.253 & \\
\hline \multirow[t]{2}{*}{ TNFa } & N Detectible & 10 & 7 & 6 & 0.084 & \\
\hline & Concentration $^{*}$ & $52.34(0.0,317.1)$ & $20.2(4.74,115.1)$ & $0.065(0.0,140.2)$ & 0.370 & \\
\hline
\end{tabular}

"Data are presented as median (IQR) in $\mathrm{pg} / \mathrm{mL}$.

${ }^{* *} \mathrm{p}$ values obtained from Chi squared tests for $\mathrm{N}$ detectible data, Kruskal-Wallis tests for concentration comparisons.

${ }^{* * *}$ Dunn's post-test comparisons with $\mathrm{p}<0.05$ are indicated for each significant Kruskal-Wallis result Statistical tests with $\mathrm{p} \leq 0.1$ (trend) are indicated in bold. 


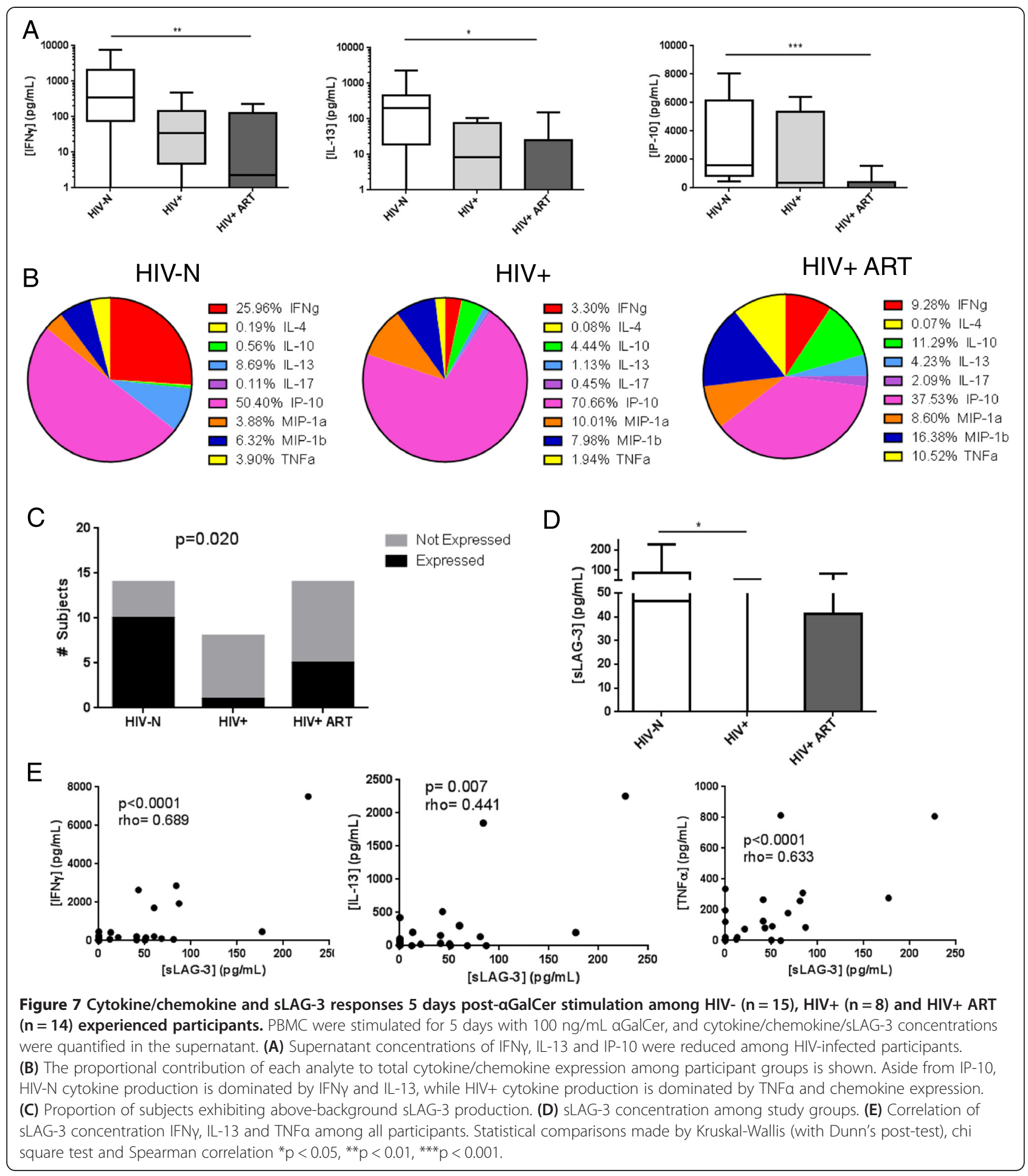

MIP-1 $\beta$ to the total cytokine environment. Although the relative proportions of IFN $\gamma$ and IL-13 were somewhat restored in the ART experienced group, there was a strong expansion in the contribution of IL-10, MIP- $1 \alpha$, MIP-1 $\beta$ and TNF $\alpha$ to the total cytokine/chemokine environment that did not reflect either the HIV-N or HIV+ ART naïve groups.
We assessed whether ex vivo iNKT LAG-3 or PD-1 expression was related to cumulative $\alpha \mathrm{GalCer}$-induced cytokine/chemokine expression, although changes in LAG-3 and PD-1 expression over the course of cell culture and the contribution of non-iNKT cells to cytokine concentrations require that the data be interpreted with caution. Interestingly, iNKT LAG-3 expression continued 
to inversely correlate with IFNY and IP-10 concentrations $(\mathrm{r}=-0.492, \mathrm{p}=0.004$ and $\mathrm{r}=-0.458, \mathrm{p}=0.014$, respectively), and trended toward an inverse correlation with IL-13 ( $\mathrm{p}=0.089$ ) among all participants (Additional file 4). In contrast, PD- 1 positively correlated with IFN $\gamma$, IL-4 and IP-10 concentrations among all participants $(r=0.399$, $\mathrm{p}=0.024 ; \mathrm{r}=0.512, \mathrm{p}=0.003 ;$ and $\mathrm{r}=0.451, \mathrm{p}=0.016$, respectively) (Additional file 4).

sLAG-3 concentration was quantified in the 5 day $\alpha$ GalCer stimulated cultures to determine whether large quantities of sLAG-3 were associated with a reduction in cytokine secretion. sLAG-3 production above background was detectible in 16/37 samples. Chi square analysis of the proportion of participants exhibiting above-background sLAG-3 levels showed significant differences between groups $(p=0.020)$, with HIV+ ART naïve patients being highly unlikely to produce sLAG-3 in response to stimulation (Figure 7C). sLAG-3 concentration varied significantly across groups $(p=0.017)$, with post-tests demonstrating significant differences between HIV-N and HIV+ ART naïve groups $(\mathrm{p}<0.05)$ (Figure 7D). Following adjustment for ex vivo iNKT frequency, significant differences in sLAG-3 production remained ( $p=0.026$, HIV-N vs HIV+ post-test $\mathrm{p}<0.05)$. Among all participants, sLAG-3 concentration significantly and positively correlated with all analytes except IL-10 and IL-4 (Additional file 5, Figure 7E). Among HIV-N participants, sLAG-3 significantly correlated with only IFN $\gamma$ and TNF $\alpha$ (Additional file 5).

\section{Discussion}

The major goals of this study were to assess T cell LAG-3 expression in a population with high immune activation and to compare LAG-3 expression levels on T cell, NK and iNKT cell populations during chronic infection and treatment. To our knowledge, this is the first report of $\mathrm{T}$ cell LAG-3 expression in an African cohort that is known to have high levels of immune activation. Although T cell LAG-3 expression was significantly elevated among HIVinfected participants compared to healthy controls, its expression remained extremely low among all individuals. These results are consistent with some reports of CD4+ LAG-3+ and CD8 + LAG-3+ T cell frequency during HIV infection [20], but not all [21]. It is interesting that the participants with the highest levels of LAG-3 expression were ART experienced, given that exhaustion and activation marker expression generally declines following ART initiation, even though immune function is not fully restored $[2,3]$. Although the cohort described by Yamamoto et al. [21] did demonstrate a decline of LAG-3 expression on bulk CD8+ T cells, they noted that LAG-3 expression on central memory cells (the memory subset with highest LAG-3 expression) did not decline among
ART experienced patients, further suggesting that LAG-3 expression is not affected by viral suppression.

Surprisingly, the frequency of LAG-3+ cells in any lymphocyte subset studied was unrelated to disease progression (measured by CD4 count or CD8+ HLA DR expression) or ART duration. This is highly unusual compared to other exhaustion markers, which generally correlate well with multiple measures of disease progression and viremia $[50,65,66]$. Although LAG-3 expression correlated with CD69 expression, the two markers were rarely co-expressed. This likely reflects upregulation of LAG-3 following acute cellular activation, but with expression kinetics that are distinct from those of CD69.

The weak correlation between iNKT LAG-3 expression and plasma IL-10 concentration was the only correlation observed between lymphocyte LAG-3 expression and plasma cytokines or chemokines. It is, therefore, difficult to determine what biological marker drives LAG-3 expression. It is possible that LAG-3 expression on iNKT cells directly regulates IL-10 production, but perhaps more likely that the relationship with IL-10 reflects cross-talk between iNKT cells and other IL-10-producing lymphocyte subsets such as Tregs or neutrophils, both of which can interact with iNKTs $[67,68]$. Given that IL-10 can correlate with viral load [69], it is also possible that this relationship reflects a dependence of LAG-3 expression on disease progression, although that seems less likely given the lack of correlation between LAG-3 and CD4 count in this cohort.

Unlike Tim-3 [70], LAG-3 was not highly expressed on any NK cell subset. The differences in LAG-3 expression between NK subsets, however, warrant further investigation. Although LAG-3 expression was not elevated on CD56-CD16+ NK cells among HIV+ participants, its expression was highest on this subset among healthy controls. The expansion of this subset during HIV infection has been documented [71], and LAG-3 could contribute to the anergic phenotype observed among these cells.

In contrast to the T cell, and to some extent NK cell, subsets, LAG-3 was expressed at moderate levels on iNKT cells, particularly among the HIV-infected participants. In some patients, up to $40 \%$ of the iNKT population was LAG-3+, raising the possibility that iNKT cell function may be regulated by LAG-3 to a greater extent than other lymphocyte populations. iNKT cells express surface markers characteristic of both $\mathrm{T}$ and NK cells and respond to lipid antigen presentation by CD1d. Despite the low frequency of the iNKT population in the periphery (0.01 - $1 \%$ of CD3+ lymphocytes in humans), iNKT activity is now appreciated to play an important role in immunity to infectious diseases [72]. During chronic HIV infection, the CD4+ iNKT subset is depleted $[28,29]$, as observed in our present cohort. While some cohorts report full recovery of both $\mathrm{CD} 4+$ and 
CD4- iNKT subsets following ART [31], others report no effect of therapy $[28,30]$ similar to the lack of CD4+ iNKT reconstitution seen during this study.

Surprisingly, the increase in LAG-3 expression did not correspond to increased PD-1 expression, in contrast to another report by Moll et al. [30]. In both cohorts, iNKT PD-1 expression was several-fold higher than T cell PD-1 expression, but PD-1 was more readily detected on both cell subsets in our cohort. Differences in cohort ethnicity could contribute to the contrasting observations, but it is also plausible that the use of the EH12.2H7 anti-PD-1 clone coupled to the extremely bright Brilliant Violet 421 fluorochrome enabled more sensitive detection of PD-1 expression in this study than other clones and fluorochromes.

To determine the impact of iNKT LAG-3 expression, we assessed functional iNKT cytokine production capacity in the Majengo cohort. Studies of iNKT function during HIV infection and treatment in the literature suffer from lack of replication in multiple cohorts, and the only functional study performed in an African cohort reported only PMA/Io-stimulated cytokine production from ART-naïve subjects [33]. The decrease in $\alpha$ GalCerinduced IFN $\gamma$ expression is similar to other cohorts, but the lack of functional reconstitution among ART experienced participants in this cohort is concerning [30,34]. Data on iNKT recovery during ART is inconsistent, as some studies suggest an improvement of iNKT cytokine production following ART [32,73], while other studies have failed to find ART-based improvement of iNKT function [30], or have not differentiated between treated and untreated subjects [34].

In this study, the ex vivo expression of LAG-3 on the iNKT subset inversely correlated with IFN $\gamma$ secretion as measured by ICS following $\alpha \mathrm{GalCer}$ stimulation. The consistent relationship between LAG-3 expression and IFN $\gamma$ secretion for both CD4+ and CD4- iNKTs suggests a similar consequence of LAG-3 expression on both subsets, despite differences in IFNY production between subsets in healthy individuals. The inhibitory activity of LAG-3 on iNKT IFNg expression was further confirmed by the demonstration that LAG-3+ iNKTs are highly unlikely to produce IFN $\gamma$ following PMA/Io stimulation. The association of LAG-3, but not PD-1, with iNKT dysfunction during HIV infection is broadly consistent with a previous study of iNKT PD-1 expression [30]. Although PD-1 expression was elevated among HIVinfected subjects in that cohort, its expression did not correlate with cytokine production or proliferation, and blocking of the PD-1/PD-L1 pathway did not improve proliferation or IFN $\gamma$ secretion. To date, the contribution of other exhaustion markers (Tim-3, CD160, 2B4) to iNKT function during HIV infection has not been defined. The contribution of Tim-3 to iNKT inhibition during herpes simplex virus infection was assessed, but found to be not responsible for the defects in cytokine secretion [74].

The only surface marker previously demonstrated to inversely correlate with iNKT cytokine production during HIV infection is the costimulatory molecule CD161 [34]. CD161 is expressed by a variable, but generally high, proportion of iNKT cells $[34,75,76]$. The regulatory nature of CD161 on iNKT cells has not been fully clarified, as CD161+ iNKT cells are more likely to produce IFN $\gamma$ and TNFo than CD161- cells in healthy individuals $[76,77]$. Our study, however, did not assess CD161 expression and therefore cannot confirm or rule out a contribution of CD161 upregulation to iNKT dysfunction.

To complement the ICS data, we also assessed cytokine/chemokine expression in cell culture supernatant after 5 days of $\alpha \mathrm{GalCer}$ stimulation. In this assay, the background subtracted supernatant protein levels represent both iNKT cytokine expression and protein expression by other cell subsets in response to iNKT activation. As such, this data represents the downstream, cumulative impact of lipid stimulation/iNKT activation in a mixed culture. Give that iNKT activation is known to regulate a large number of other cell types, and that the functional impact of LAG-3 expression (which binds MHCII proteins) can only be truly assessed when MHCII-expressing cells are present, measuring cytokines in a whole PBMC culture may be more relevant than sorting and isolating iNKT cells. The correlation between iNKT frequency and analyte concentration strongly suggests that the measured analyte levels are iNKT-induced.

Overall, several patterns emerged from analysis of cytokine/chemokine expression levels and correlations. Among HIV-N participants, IFN $\gamma$ and IL-13 were the major cytokines produced in culture after IP-10. IFN- $\gamma$ is a hallmark cytokine produced upon $\alpha \mathrm{GalCer}$ stimulation, and IL-13 is produced by activated iNKT cells and directs monocyte to DC differentiation [78]. The loss of IL-13 secretion among HIV+ participants likely reflects, at least partially, the depletion of the CD4+ iNKT subset, which is reportedly the sole iNKT subset to produce IL-13 [64,79]. In contrast, cytokine production among HIV+ ART naïve participants was mostly limited to IP-10 and MIP- $1 \alpha /$ $\beta$ production. The ART experienced group never produced significantly higher levels of any analyte compared the ART naïve group, and showed little evidence of iNKT reconstitution. These data suggest that in addition to a lack of reconstitution of iNKT function among ART experienced patients, the cytokine production profile is altered in comparison to both HIV-N and ART-naïve subjects.

The correlations between sLAG-3 production and cytokine/chemokine concentrations among all study groups suggest that sLAG-3 may simply be a marker of iNKT activation. There is no evidence that increasing 
concentrations of sLAG-3 in culture results in inhibition of cytokine production. The lack of production of sLAG-3 in HIV+ ART naïve, but not ART-treated, participants is distinct compared to other cytokine/chemokine responses, which were generally absent in the ART treated group. The production of sLAG-3 by iNKT cells following stimulation has not been described in the literature, and represents a significant gap in knowledge.

The correlation between LAG-3 expression and supernatant IFN $\gamma$ at 5 days post-stimulation is consistent with the ICS results described above. It is important to note, however, that changes in LAG-3 expression during culture, and the contribution of other PBMC cell subsets to cytokine production make a direct link between LAG-3 expression and long-term cytokine production difficult. The positive correlations between PD-1 expression and cytokine production also suggest that PD-1 may indicate a more activated, rather than exhausted, iNKT phenotype.

In conclusion, we have demonstrated both short-term and long-term defects in iNKT cytokine/chemokine expression in response to lipid stimulation in a Kenyan cohort of HIV+ ART naïve and experienced women. Although PD-1 expression did not appear to mediate iNKT dysfunction, the elevated expression of LAG-3 was associated with an inhibition of IFNY production, suggesting that LAG-3 at least partially regulates iNKT function during chronic infection. Coupled with previous observations from our lab, and others, that LAG-3 is poorly expressed on T cells during HIV infection, blockade of LAG-3 signaling may selectively restore innate immune function and, therefore, improve current treatment regimens.

\section{Conclusions}

Overall, our data suggest that LAG-3 is unlikely to play a significant role in $\mathrm{T}$ cell immune exhaustion in an African population. Unexpectedly, LAG-3 upregulation during chronic HIV infection and treatment may be restricted to the iNKT innate lymphocyte subset. The maintenance of LAG-3 expression during ART suggests that it may contribute to the innate immune dysregulation observed among ART subjects, as well as contributing to the loss of iNKT cytokine production observed during chronic infection. Future studies that demonstrate the cell-intrinsic activity of LAG-3 expression will determine whether blocking LAG-3 activity could improve innate immune responses initiated by iNKT cells during HIV infection or treatment.

\section{Methods}

Study subjects $(\mathrm{n}=90)$

This study recruited 10 HIV-uninfected, 40 HIV-infected antiretroviral naïve and $40 \mathrm{HIV}$-infected antiretroviral experienced patients from the Majengo commercial sex worker cohort located in Nairobi, Kenya. In a follow-up study, an additional 16 HIV-N, 9 HIV+ and $17 \mathrm{HIV+}$ ART participants were recruited. The Majengo cohort is an open cohort established in 1984 that recruits both HIV- and HIV+ commercial sex workers. During a routine clinic visit, participants provided peripheral blood samples, and CD4 count was determined for HIV+ participants. The study was approved by ethics boards at both the University of Manitoba and the University of Nairobi, and all participants provided informed consent.

\section{Flow cytometric analysis}

Peripheral blood mononuclear cells (PBMCs) were isolated from whole blood by Ficoll gradient separation. After isolation, cells were immediately stained for ex vivo flow cytometric analysis and plasma samples were collected and frozen for cytokine bead array assay. The following fluorochrome-conjugated antibodies were used in various combinations: LAG-3 FITC (clone 17B4, Enzo Life sciences), iNKT TCR PE (clone 6B11), CD69 PeCy5, CD3 Pacific Blue, CD8 V500, CD56 APC, CD4 Alexa700, CD16 APC-H7, HLA DR APC-H7, CD3 Alexa700, CD3 PeCy5, TNFa PeCy7, IFNy Alexa700 (all from BD Biosciences), and PD-1 Brilliant Violet 421 (clone EH12.2H7, Biolegend), Live Dead viability dye (Invitrogen). Depending on the experiment, $1-2 \times 10^{6}$ cells were stained for surface markers for 30 minutes at $4^{\circ} \mathrm{C}$. Cells were resuspended in $1 \%$ paraformaldehyde solution and acquired on the BD LSRII flow cytometer. A minimum of 100,000 lymphocyte events were collected using BD FACS Diva. Analysis was performed using FlowJo version 7.5 (Treestar).

For stimulation experiments, cells were either stimulated with $25 \mathrm{ng} / \mathrm{mL}$ PMA and $500 \mathrm{ng} / \mathrm{mL}$ ionomycin for 6 hours, or $100 \mathrm{ng} / \mathrm{mL}$ of $\alpha \mathrm{GalCer}$ for 10 hours. Golgi stop and golgi plug were added to the cell culture 2 hours post-stimulation to capture cytokine production. Cells were surface stained above, permeabilized with BD Cytofix/Cytoperm solution and stained for IFN $\gamma$ and TNF $\alpha$ for 30 minutes at $4^{\circ} \mathrm{C}$. Because $\alpha \mathrm{GalCer}$ stimulation was observed to strongly downregulate the iNKT TCR, the 6B11 antibody was added at the time of stimulation to identify cells with downregulated TCR, similar to protocols for $\mathrm{CD} 8+\mathrm{T}$ cell tetramer staining. Cells were also stimulated with $100 \mathrm{ng} / \mathrm{mL} \alpha \mathrm{GalCer}$ for 5 days and the culture supernatant collected for quantification of cytokine secretion by bead array.

\section{Plasma cytokine and chemokine concentrations}

Concentrations of cytokines and chemokines in plasma samples were quantified using Milliplex MAP bead array kits (Millipore) according the manufacturer's 2 hour protocol. The Human Cytokine/Chemokine bead panel included the following analytes (with given limits of 
detection): IFN 2 (7.2 pg/mL), IFN $\gamma(2.4 \mathrm{pg} / \mathrm{mL})$, IL-4 (0.6 pg/mL), IL-6 (0.4 pg/mL), IL-10 (0.5 pg/mL), MIP$1 \beta(4.8 \mathrm{pg} / \mathrm{mL}), \mathrm{sCD} 40 \mathrm{~L}(9.9 \mathrm{pg} / \mathrm{mL})$ and TNF $\alpha(1.6 \mathrm{pg} /$ $\mathrm{mL})$. Cell culture supernatants from the iNKT $\alpha \mathrm{GalCer}$ stimulations were analysed for expression of the following analytes (with corresponding sensitivities): IFN $\gamma$ (0.8 pg/mL), IL-4 (4.5 pg/mL), IL-10 (1.1 pg/mL), IL-13 (1.3 pg/mL), IL-17 (0.7 pg/mL), IP-10 (8.6 pg/mL), IL-12p70 (0.6 pg/mL), MIP-1 $\alpha(2.9 \mathrm{pg} / \mathrm{mL})$, MIP- $1 \beta$ $(3.0 \mathrm{pg} / \mathrm{mL})$ and TNF $\alpha(0.7 \mathrm{pg} / \mathrm{mL})$. Plates quantifying cytokines in cell culture supernatants used RPMI-1640 media $+10 \%$ FBS as the matrix for standard, control and background wells. Data were acquired on a Bio-Plex 200 (Bio-Rad) and analysed with Bioplex Manager software (version 5.0, Bio-Rad). Standard curves for each analyte were generated using 5 parameter logistic regressions. Samples below the limit of detection were assigned a value of half of the detection limit.

\section{Soluble LAG-3 ELISA}

Quantification of sLAG-3 was performed by in-house optimized ELISA. 96 well plates were coated with $5 \mu \mathrm{g} / \mathrm{mL}$ of coating antibody (anti-LAG-3 clone 11E3, Enzo Life sciences) and incubated with $100 \mu \mathrm{L}$ of sample. A 10-point standard curve was generated using doubling dilutions of recombinant human LAG-3-Fc (Enzo Life Sciences) from $8 \mathrm{ng} / \mathrm{mL}$ to $15.6 \mathrm{pg} / \mathrm{mL}$ diluted in RPMI- $1640+10 \% \mathrm{FBS}$ media. sLAG-3 was detected by the addition of $0.5 \mu \mathrm{g} / \mathrm{mL}$ of anti-LAG-3-biotin (clone 17B4) and streptavidin HRP. Super sensitive TMB (Sigma) was used as the colorimetric substrate and after the addition of a $3 \% \mathrm{HCl}$ stop solution, the optical density was measured at $450 \mathrm{~nm}$.

\section{Statistical analysis}

Statistical analyses were performed using GraphPad Prism version 6.0. Two and three group comparisons were performed using the non-parametric Mann-Whitney and Kruskal-Wallis (with Dunn's post-test in the event of a significant Kruskal-Wallis p value) tests, respectively. Correlations were performed using Spearman's rho value. Comparison of intra-patient (matched) data was carried out by Wilcoxon matched-pairs test (2 groups) or Friedman test (3 groups). Categorical variables (such as the presence or absence of an above-background cytokine response) were compared by chi squared analysis. $\mathrm{p}$ values $<0.05$ were considered to be statistically significant.

\section{Additional files}

Additional file 1: Representative ex vivo staining of PBMC samples to identify lymphocyte populations. Singlets were identified by FSC-A versus FSC-H plot. Lymphocytes were gated by FSC-A versus SSC-A. The CD3- population was subgated into three NK cell subsets based on CD56 and CD16 expression. The CD3+ population was subgated into CD3 +
$6 \mathrm{~B} 11+\mathrm{iNKT}$ cells and CD3+6B11- T cells. Both populations were further gated by CD4 and CD8 staining.

Additional file 2: (A) PD-1 expression on CD8+ T cells among HIV-infected participants compared to healthy controls. (B) Correlation between PD-1 and LAG-3 expression on CD8+ T cells among all participants. (C) Representative staining of LAG-3 on CD8+ T cells, and PD-1 expression on CD8 + LAG-3+ T cells. (D) PD-1 expression on CD8 + LAG-3+ T cells compared to bulk CD8+ T cells. Statistical comparisons made by Mann-Whitney test, Wilcoxon test and Spearman correlation. ${ }^{*} p<0.05,{ }^{* *} p<0.01,{ }^{* * * *} p<0.0001$.

Additional file 3: Representative surface and cytokine staining of iNKT stimulations. Singlets were identified by FSC-A versus FCS-H gating, followed by gating on the lymphocyte population. Aberrant fluorescence signals were excluded by gating on FITC fluorescence over time. Dead cells were excluded by Live/Dead viability staining. iNKT cells were gated as CD3 +6B11+. Intracellular staining of IFNy and TNFa and surface staining of LAG-3 and PD-1 is shown for media (negative control), PMA/ionomycin and aGalCer stimulations.

Additional file 4: Correlations between ex vivo iNKT LAG-3 and PD-1 expression with 5 day post-aGalCer stimulation cytokine production among all participants.

Additional file 5: Correlation between background-subtracted sLAG-3 concentrations at 5 days post aGalCer-stimulation and supernatant cytokines/chemokines.

\section{Competing interests}

The authors declare that they have no competing interests.

\section{Authors' contributions}

$J J$ led the design of the study, conducted the experiments, analysed the data and drafted the manuscript. JW and AS assisted with conducting the experiments and analysing data. MK recruited study participants and collected biological samples. JK and FP participated in the design and co-ordination of the study and participant recruitment. KF participated in the design of the study, analysis of the data and helped to draft the manuscript. All authors read and approved the final manuscript.

\section{Acknowledgements}

The authors would like to acknowledge the technical support of Julie Lajoie. KF was supported by the Manitoba Health Research Council with a Manitoba Research Chair. JJ is supported by an MHRC studentship. Funding was provided by CIHR grant HVI-81377.

\section{Author details}

'Department of Medical Microbiology, University of Manitoba, 539 - 745 Bannatyne Avenue, Winnipeg, Manitoba R3E 0 J9, Canada. ${ }^{2}$ National HIV and Retrovirology Laboratory, JC Wilt Infectious Disease Research Centre, Winnipeg, Manitoba, Canada. ${ }^{3}$ Department of Medical Microbiology, University of Nairobi, Nairobi, Kenya. ${ }^{4}$ Department of Community Health Sciences, University of Manitoba, S113 - 750 Bannatyne Avenue, Winnipeg, Manitoba R3E 0 W3, Canada.

Received: 9 October 2014 Accepted: 16 January 2015

Published online: 13 February 2015

\section{References}

1. Khaitan A, Unutmaz D. Revisiting Immune Exhaustion During HIV Infection. Curr HIV/AIDS Rep. 2011;8:4-11.

2. Kassu A, Marcus RA, D'Souza MB, Kelly-McKnight EA, Palmer BE. Suppression of HIV replication by antiretroviral therapy reduces TIM-3 expression on HIV-specific CD8(+) T cells. AIDS Res Hum Retroviruses. 2011;27:1-3.

3. Rehr M, Cahenzli J, Haas A, Price DA, Gostick E, Huber M, et al. Emergence of polyfunctional CD8+ T cells after prolonged suppression of human immunodeficiency virus replication by antiretroviral therapy. J Virol. 2008;82:3391-404.

4. Porichis F, Kaufmann DE. Role of PD-1 in HIV pathogenesis and as target for therapy. Curr HIV/AIDS Rep. 2012;9:81-90. 
5. Triebel F, Jitsukawa S, Baixeras E, Roman-Roman S, Genevee C, Viegas-Pequignot E, et al. LAG-3, a novel lymphocyte activation gene closely related to CD4. J Exp Med. 1990;171:1393-405.

6. Baixeras E, Huard B, Miossec C, Jitsukawa S, Martin M, Hercend T, et al. Characterization of the lymphocyte activation gene 3-encoded protein. $A$ new ligand for human leukocyte antigen class II antigens. J Exp Med. 1992;176:327-37.

7. Huard B, Prigent P, Tournier M, Bruniquel D, Triebel F. CD4/major histocompatibility complex class II interaction analyzed with CD4- and lymphocyte activation gene-3 (LAG-3)-Ig fusion proteins. Eur J Immunol. 1995;25:2718-21.

8. Hannier S, Tournier M, Bismuth G, Triebel F. CD3/TCR complex-associated lymphocyte activation gene-3 molecules inhibit CD3/TCR signaling. J Immunol. 1998;161:4058-65.

9. Macon-Lemaitre $L$, Triebel $F$. The negative regulatory function of the lymphocyte-activation gene-3 co-receptor (CD223) on human T cells. Immunology. 2005;115:170-8.

10. Huard B, Mastrangeli R, Prigent P, Bruniquel D, Donini S, El-Tayar N, et al. Characterization of the major histocompatibility complex class II binding site on LAG-3 protein. Proc Natl Acad Sci U S A. 1997;94:5744-9.

11. Camisaschi C, Casati C, Rini F, Perego M, De Filippo A, Triebel F, et al. LAG-3 expression defines a subset of CD4(+)CD25(high)Foxp3(+) regulatory T cells that are expanded at tumor sites. J Immunol. 2010;184:6545-51.

12. Sumitomo S, Yamamoto K. CD4+CD25-LAG-3+ T cells in mouse and human. Nihon Rinsho Meneki Gakkai Kaishi. 2010;33:92-8.

13. Montoya CJ, Pollard D, Martinson J, Kumari K, Wasserfall C, Mulder CB, et al. Characterization of human invariant natural killer T subsets in health and disease using a novel invariant natural killer T cell-clonotypic monoclona antibody, 6B11. Immunology. 2007;122:1-14.

14. Camisaschi C, De filippo A, Beretta V, Rini F, Tazzari M, Arienti F, et al. LAG-3 expression and role in human pDC biology. Front. Immunol. Conference Abstract: 15th International Congress of Immunology (ICI). doi:10.3389/conf. fimmu.2013.02.00811.

15. Li Q, Smith AJ, Schacker TW, Carlis JV, Duan L, Reilly CS, et al. Microarray analysis of lymphatic tissue reveals stage-specific, gene expression signatures in HIV-1 infection. J Immunol. 2009;183:1975-82.

16. Bosinger SE, Li Q, Gordon SN, Klatt NR, Duan L, Xu L, et al. Global genomic analysis reveals rapid control of a robust innate response in SIV-infected sooty mangabeys. J Clin Invest. 2009;119:3556-72.

17. Rotger M, Dalmau J, Rauch A, McLaren P, Bosinger SE, Martinez R, et al. Comparative transcriptomics of extreme phenotypes of human HIV-1 infection and SIV infection in sooty mangabey and rhesus macaque. J Clin Invest. 2011;121:2391-400.

18. Shankar EM, Che KF, Messmer D, Lifson JD, Larsson M. Expression of a broad array of negative costimulatory molecules and Blimp-1 in T cells following priming by HIV-1 pulsed dendritic cells. Mol Med(Cambridge, Mass). 2011;17:229-40.

19. Price P, Keane N, Gray L, Lee S, Gorry PR, French MA. CXCR4 or CCR5 tropism of human immunodeficiency virus type 1 isolates does not determine the immunological milieu in patients responding to antiretroviral therapy. Viral Immunol. 2006;19:734-40.

20. Lim AY, Price P, Beilharz MW, French MA. Cell surface markers of regulatory $T$ cells are not associated with increased forkhead box $\mathrm{p3}$ expression in blood CD4+ T cells from HIV-infected patients responding to antiretroviral therapy. Immunol Cell Biol. 2006;84:530-6.

21. Yamamoto T, Price DA, Casazza JP, Ferrari G, Nason M, Chattopadhyay PK, et al. Surface expression patterns of negative regulatory molecules identify determinants of virus-specific CD8+ T-cell exhaustion in HIV infection. Blood. 2011;117:4805-15.

22. Porichis F, Kwon DS, Zupkosky J, Tighe DP, McMullen A, Brockman MA, et al. Responsiveness of HIV-specific CD4 T cells to PD-1 blockade. Blood. 2011;118:965-74

23. Pena J, Jones N, Bousheri S, Bangsberg DR, Cao H. LAG-3 expression defines a discrete subset of HIV-specific CD8+ T cells that is associated with lower viral load. AIDS Res Hum Retrovir. 2013;30(6):535-41.

24. Kottilil S, Chun TW, Moir S, Liu S, McLaughlin M, Hallahan CW, et al. Innate immunity in human immunodeficiency virus infection: effect of viremia on natural killer cell function. J Infect Dis. 2003;187:1038-45.

25. Alter G, Teigen N, Davis BT, Addo MM, Suscovich TJ, Waring MT, et al. Sequential deregulation of NK cell subset distribution and function starting in acute HIV-1 infection. Blood. 2005;106:3366-9.
26. Dillon SM, Lee EJ, Bramante JM, Barker E, Wilson CC. The Natural Killer Cell Interferon-gamma Response to Bacteria is Diminished in Untreated HIV-1 Infection and Defects Persist Despite Viral Suppression. J Acquir Immune Defic Syndr. 2013;65(3):259-67.

27. Mavilio D, Lombardo G, Benjamin J, Kim D, Follman D, Marcenaro E, et al Characterization of CD56-/CD16+ natural killer (NK) cells: a highly dysfunctional NK subset expanded in HIV-infected viremic individuals. Proc Natl Acad Sci U S A. 2005;102:2886-91.

28. van der Vliet HJ, von Blomberg BM, Hazenberg MD, Nishi N, Otto SA, van Benthem $\mathrm{BH}$, et al. Selective decrease in circulating $\mathrm{V}$ alpha $24+\mathrm{V}$ beta $11+$ NKT cells during HIV type 1 infection. J Immunol. 2002;168:1490-5.

29. Sandberg JK, Fast NM, Palacios EH, Fennelly G, Dobroszycki J, Palumbo P, et al. Selective loss of innate CD4(+) V alpha 24 natural killer T cells in human immunodeficiency virus infection. J Virol. 2002;76:7528-34.

30. Moll M, Kuylenstierna C, Gonzalez VD, Andersson SK, Bosnjak L, Sonnerborg A, et al. Severe functional impairment and elevated PD-1 expression in CD1d-restricted NKT cells retained during chronic HIV-1 infection. Eur Immunol. 2009;39:902-11.

31. Chiappini E, Betti L, Bonsignori F, Azzari C, Galli L, de Martino M. CD4(+) and CD4(-) CD1D-restricted natural killer T cells in perinatally HIV-1 infected children receiving highly active antiretroviral therapy. Int J Immunopathol Pharmacol. 2010;23:665-9.

32. Vasan S, Poles MA, Horowitz A, Siladji EE, Markowitz M, Tsuji M. Function of NKT cells, potential anti-HIV effector cells, are improved by beginning HAART during acute HIV-1 infection. Int Immunol. 2007;19:943-51.

33. Mureithi MW, Cohen K, Moodley R, Poole D, Mncube Z, Kasmar A, et al. Impairment of CD1d-restricted natural killer T cells in chronic HIV type 1 clade C infection. AIDS Res Hum Retroviruses. 2011;27:501-9.

34. Snyder-Cappione JE, Loo CP, Carvalho Kl, Kuylenstierna C, Deeks SG, Hecht FM, et al. Lower cytokine secretion ex vivo by natural killer T cells in HIV-infected individuals is associated with higher CD161 expression. AIDS (London, England). 2009;23:1965-70.

35. Snyder-Cappione JE, Tincati C, Eccles-James IG, Cappione AJ, Ndhlovu LC, Koth $\mathrm{LL}$, et al. A comprehensive ex vivo functional analysis of human NKT cells reveals production of MIP1-alpha and MIP1-beta, a lack of IL-17, and a Th1-bias in males. PLoS One. 2010;5:e15412.

36. Tessmer MS, Fatima A, Paget C, Trottein F, Brossay L. NKT cell immune responses to viral infection. Expert Opin Ther Targets. 2009;13:153-62.

37. Chang YJ, Huang JR, Tsai YC, Hung JT, Wu D, Fujio M, et al. Potent immunemodulating and anticancer effects of NKT cell stimulatory glycolipids. Proc Natl Acad Sci U S A. 2007:104:10299-304.

38. Takahashi T, Nieda M, Koezuka Y, Nicol A, Porcelli SA, Ishikawa Y, et al. Analysis of human $V$ alpha 24+ CD4+ NKT cells activated by alpha-glycosylceramidepulsed monocyte-derived dendritic cells. J Immunol. 2000;164:4458-64.

39. Matsuda JL, Mallevaey T, Scott-Browne J, Gapin L. CD1d-restricted iNKT cells, the 'Swiss-Army knife' of the immune system. Curr Opin Immunol. 2008;20:358-68.

40. Gumperz JE, Miyake S, Yamamura T, Brenner MB. Functionally distinct subsets of CD1d-restricted natural killer T cells revealed by CD1d tetramer staining. J Exp Med. 2002;195:625-36.

41. Rout N, Else JG, Yue S, Connole M, Exley MA, Kaur A. Heterogeneity in phenotype and function of CD8+ and CD4/CD8 double-negative Natural Killer T cell subsets in sooty mangabeys. J Med Primatol. 2010;39:224-34.

42. Kuylenstierna C, Bjorkstrom NK, Andersson SK, Sahlstrom P, Bosnjak L, Paquin-Proulx D, et al. NKG2D performs two functions in invariant NKT cells: direct TCR-independent activation of NK-like cytolysis and co-stimulation of activation by CD1d. Eur J Immunol. 2011:41:1913-23.

43. Hermans IF, Silk JD, Gileadi U, Salio M, Mathew B, Ritter G, et al. NKT cells enhance CD4+ and CD8+ T cell responses to soluble antigen in vivo through direct interaction with dendritic cells. J Immunol. 2003;171:5140-7.

44. Joyee AG, Qiu H, Fan Y, Wang S, Yang X. Natural killer T cells are critical for dendritic cells to induce immunity in Chlamydial pneumonia. Am J Respir Crit Care Med. 2008;178:745-56.

45. Joyee AG, Uzonna J, Yang X. Invariant NKT cells preferentially modulate the function of CD8 alpha+ dendritic cell subset in inducing type 1 immunity against infection. J Immunol. 2010;184:2095-106.

46. Carnaud C, Lee D, Donnars O, Park SH, Beavis A, Koezuka Y, et al. Cutting edge: Cross-talk between cells of the innate immune system: NKT cells rapidly activate NK cells. J Immunol. 1999;163:4647-50.

47. Joshi SK, Lang GA, Devera TS, Johnson AM, Kovats S, Lang ML. Differential contribution of dendritic cell CD1d to NKT cell-enhanced humoral immunity and CD8+ T cell activation. J Leukoc Biol. 2012;91(5):783-90. 
48. Stober D, Jomantaite I, Schirmbeck R, Reimann J. NKT cells provide help for dendritic cell-dependent priming of MHC class I-restricted CD8+ T cells in vivo. J Immunol. 2003;170:2540-8.

49. Koesters SA, Matu L, Kiama P, Anzala O, Embree J, Plummer FA, et al. Elevation of immune activation in kenyan women is associated with alterations in immune function: implications for vaccine development. J Clin Immunol. 2004;24:702-9.

50. Jones RB, Ndhlovu LC, Barbour JD, Sheth PM, Jha AR, Long BR, et al. Tim-3 expression defines a novel population of dysfunctional $T$ cells with highly elevated frequencies in progressive HIV-1 infection. J Exp Med. 2008;205:2763-79.

51. Kassu A, Marcus RA, D'Souza MB, Kelly-McKnight EA, Golden-Mason L, Akkina $R$, et al. Regulation of virus-specific CD4+ T cell function by multiple costimulatory receptors during chronic HIV infection. J Immunol. 2010;185:3007-18.

52. Alter G, Altfeld M. NK cells in HIV-1 infection: evidence for their role in the control of HIV-1 infection. J Intern Med. 2009;265:29-42.

53. Ndhlovu LC, Lopez-Verges S, Barbour JD, Jones RB, Jha AR, Long BR, et al. Tim-3 marks human natural killer cell maturation and suppresses cellmediated cytotoxicity. Blood. 2012;119:3734-43.

54. Bienemann K, louannidou K, Schoenberg K, Krux F, Reuther S, Feyen O, et al. iNKT cell frequency in peripheral blood of Caucasian children and adolescent: the absolute iNKT cell count is stable from birth to adulthood. Scand J Immunol. 2011;74(4):406-11.

55. Thomas SY, Hou R, Boyson JE, Means TK, Hess C, Olson DP, et al. CD1d-restricted NKT cells express a chemokine receptor profile indicative of Th1-type inflammatory homing cells. J Immunol. 2003;171:2571-80.

56. Jiang X, Zhang M, Lai Q, Huang X, Li Y, Sun J, et al. Restored circulating invariant NKT cells are associated with viral control in patients with chronic hepatitis B. PLoS One. 2011;6:e28871.

57. Croudace JE, Curbishley SM, Mura M, Willcox CR, Illarionov PA, Besra GS, et al. Identification of distinct human invariant natural killer T-cell response phenotypes to alpha-galactosylceramide. BMC Immunol. 2008;9:71.

58. Engelmann P, Farkas K, Kis J, Richman G, Zhang Z, Liew CW, et al. Characterization of human invariant natural killer T cells expressing FoxP3. Int Immunol. 2011;23:473-84.

59. Gyimesi E, Nagy G, Remenyik E, Sipka S, Zeher M, Biro T, et al. Altered Peripheral Invariant Natural Killer T Cells in Atopic Dermatitis. J Clin Immunol. 2011;31(5):864-72.

60. O'Reilly V, Zeng SG, Bricard G, Atzberger A, Hogan AE, Jackson J, et al. Distinct and Overlapping Effector Functions of Expanded Human CD4+, CD8a+ and CD4-CD8a- Invariant Natural Killer T Cells. PLoS One. 2011;6:e28648.

61. Kee SJ, Kwon YS, Park YW, Cho YN, Lee SJ, Kim TJ, et al. Dysfunction of Natural Killer T Cells in Patients with Active Mycobacterium tuberculosis Infection. Infect Immun. 2012;80(6):2100-8.

62. Lee SJ, Cho YN, Kim TJ, Park SC, Park DJ, Jin HM, et al. Natural killer T cell deficiency in active adult onset Still's disease: the correlation of its deficiency with natural killer cell dysfunction. Arthritis Rheum. 2012;64(9):2868-77.

63. Rout N, Else JG, Yue S, Connole M, Exley MA, Kaur A. Paucity of CD4+ Natural Killer T (NKT) Lymphocytes in Sooty Mangabeys Is Associated with Lack of NKT Cell Depletion after SIV Infection. PLoS One. 2010;5:e9787.

64. Rout N, Greene J, Yue S, O'Connor D, Johnson RP, Else JG, et al. Loss of effector and anti-inflammatory natural killer T lymphocyte function in pathogenic simian immunodeficiency virus infection. PLoS Pathog. 2012:8:e1002928

65. Trautmann L, Janbazian L, Chomont N, Said EA, Gimmig S, Bessette B, et al. Upregulation of PD-1 expression on HIV-specific CD8+ T cells leads to reversible immune dysfunction. Nat Med. 2006;12:1198-202.

66. Peretz Y, He Z, Shi Y, Yassine-Diab B, Goulet JP, Bordi R, et al. CD160 and PD-1 Co-Expression on HIV-Specific CD8 T Cells Defines a Subset with Advanced Dysfunction. PLoS Pathog. 2012;8:e1002840.

67. De Santo C, Arscott R, Booth S, Karydis I, Jones M, Asher R, et al. Invariant NKT cells modulate the suppressive activity of IL-10-secreting neutrophils differentiated with serum amyloid A. Nat Immunol. 2010;11:1039-46.

68. La Cava A, Van Kaer L, Fu Dong S. CD4+CD25+ Tregs and NKT cells: regulators regulating regulators. Trends Immunol. 2006;27:322-7.

69. Roberts L, Passmore JA, Williamson C, Little F, Bebell LM, Mlisana K, et al. Plasma cytokine levels during acute HIV-1 infection predict HIV disease progression. AIDS (London, England). 2010;24:819-31.
70. Jost S, Moreno-Nieves UY, Garcia-Beltran WF, Rands K, Reardon J, Toth I, et al. Dysregulated Tim-3 expression on natural killer cells is associated with increased Galectin-9 levels in HIV-1 infection. Retrovirology. 2013;10:74.

71. Bjorkstrom NK, Ljunggren HG, Sandberg JK. CD56 negative NK cells: origin, function, and role in chronic viral disease. Trends Immunol. 2010;31:401-6.

72. van der Vliet HJ, Molling JW, von Blomberg BM, Nishi N, Kolgen W, van den Eertwegh AJ, et al. The immunoregulatory role of CD1d-restricted natural killer T cells in disease. Clin Immunol. 2004;112:8-23.

73. Kuylenstierna C, Snyder-Cappione JE, Loo CP, Long BR, Gonzalez VD, Michaelsson J, et al. NK cells and CD1d-restricted NKT cells respond in different ways with divergent kinetics to IL-2 treatment in primary HIV-1 infection. Scand J Immunol. 2011;73:141-6.

74. Bosnjak L, Sahlstrom P, Paquin-Proulx D, Leeansyah E, Moll M, Sandberg JK Contact-Dependent Interference with Invariant NKT Cell Activation by Herpes Simplex Virus-Infected Cells. J Immunol. 2012;188:6216-24.

75. Exley M, Porcelli S, Furman M, Garcia J, Balk S. CD161 (NKR-P1A) costimulation of CD1d-dependent activation of human T cells expressing invariant V alpha 24 J alpha Q T cell receptor alpha chains. J Exp Med. 1998;188:867-76.

76. Chan AC, Leeansyah E, Cochrane A, Duda Y, Mittag D, Harrison LC, et al. Ex-vivo analysis of human Natural Killer T cells demonstrates heterogeneity between tissues and within established CD4(+) and CD4(-) subsets. Clin Exp Immunol. 2013;172:129-37.

77. Peukert K, Wingender G, Patecki M, Wagner S, Schmitt R, Ge S, et al. Invariant natural killer $T$ cells are depleted in renal impairment and recover after kidney transplantation. Nephrol Dial Transplant. 2013;29(5):1020-8.

78. Hegde S, Chen X, Keaton JM, Reddington F, Besra GS, Gumperz JE. NKT cells direct monocytes into a DC differentiation pathway. J Leukoc Biol. 2007:81:1224-35.

79. Lee PT, Benlagha K, Teyton L, Bendelac A. Distinct functional lineages of human V(alpha)24 natural killer T cells. J Exp Med. 2002;195:637-41.

\section{Submit your next manuscript to BioMed Central and take full advantage of:}

- Convenient online submission

- Thorough peer review

- No space constraints or color figure charges

- Immediate publication on acceptance

- Inclusion in PubMed, CAS, Scopus and Google Scholar

- Research which is freely available for redistribution 